\title{
Novel substrates and nutritional support: possible role of ornithine $\alpha$-ketoglutarate
}

\author{
BY D. B. A. SILK AND J. J. PAYNE-JAMES \\ Department of Gastroenterology and Nutrition, Central Middlesex Hospital, Acton Lane, \\ London NWIO 7NS
}

There is now an increasing awareness amongst hospital-based clinicians that proteinenergy malnutrition can be a significant problem during management of patients with both medical and surgical disorders (Bistrian et al. 1976; Hill et al. 1977; Neithercut et al. 1987), and as a consequence the use of both enteral and parenteral nutrition has become widespread (Payne-James \& Silk, 1988: Wilmore, 1989).

The primary aim of any type of nutritional support is to place patients in overall nutritional balance (Rees et al. 1989a,b). Although from the medical point of view nitrogen balance is often the variable used in the monitoring process, there is general agreement that this is not necessarily the best or only method available, and in the future other methods aimed at function of muscle, protein synthesis cascade, and immunodefence systems are likely to become of more relevance to patient management.

It has been well documented that the neuro-endocrinological response to injury and sepsis frequently mitigates against achicving positive $\mathrm{N}$ balance, (Jones et al. 1983; Keohane et al. 1984) and, thus, in the clinical setting the primary aim of nutritional support has to be modified to minimizing $\mathrm{N}$ losses for as long as it takes for the underlying disease process to resolve, at which time the altered neuro-endocrinological responses will permit anabolism to occur. Given the previously stated aim clinical investigators have begun to seek ways of improving the efficacy of nutritional support (Wilmore, 1989). Using $\mathrm{N}$ balance as the end-point, a number of innovative studies have been reported over the last 14 years. In one of the early reports Greenberg et al. (1976) showed that hypoenergetic energy in the form of glucose or lipid $(<46 \mathrm{~kJ}(11 \mathrm{kcal}) / \mathrm{g}$ per d) was without effect on $\mathrm{N}$ balance when administered with amino acid- $\mathrm{N}(1 \mathrm{~g} \mathrm{~N} / \mathrm{kg}$ per d). Subsequently Hill et al. (1977) demonstrated significantly superior $\mathrm{N}$ retention in gastroenterological patients requiring total parenteral nutrition (TPN) when a combination of lipid and glucose was used as the energy source than glucose alone (MacFie et al. 1981). Considerable progress has been achieved in dispelling the controversy and confusion that have surrounded the respective merits of glucose and lipid as energy substrates, and from the point of view of $\mathrm{N}$ retention most workers now agree that up to $50 \%$ of energy can be provided in the form of lipid (Burns, 1988; Grimble et al. 1989). With regard to absolute energy requirements, a consensus has also emerged, in that for a given $\mathrm{N}$ intake, $\mathrm{N}$ balance cannot be affected in most patients by increasing energy intake, a level of $147-168 \mathrm{~kJ}(35-40 \mathrm{kcal}) / \mathrm{kg}$ per d matching energy expenditure in most patients (Elwyn et al. 1981; Hill \& Church, 1984; Shanbhogue et al. 1987). Information is beginning to emerge, however, on how $\mathrm{N}$ balance can be improved by altering the hormonal milieu of patients receiving nutritional support; both growth hormone and bradykinin being associated with significant improvements in $\mathrm{N}$ balance (Manson \& Wilmore, 1986; Ponting et al. 1988; Ziegler et al. 1988: Hartl et al. 1990). Although several investigators are beginning to demonstrate that in certain clinical settings $\mathrm{N}$ 
balance can be improved by altering the quality of $\mathrm{N}$ administered, it must be first appreciated that the quantity of $\mathrm{N}$ administered is also important. $\mathrm{N}$ balance can be improved in both head injury and burn patients by increasing $\mathrm{N}$ intake (Dominioni et al. 1985). Similar findings have also been reported in a heterogenous group of patients receiving enteral nutrition (Rees et al. 1989b).

Much current interest in the field of $\mathrm{N}$ metabolism during nutritional support is now being directed towards investigating the influences that the quality of $\mathrm{N}$ exert. Examples of how the quality of administered $\mathrm{N}$ has been altered includes the use of glutamine and branched-chain amino acid-enriched amino acid- $\mathrm{N}$ as well as glutamine containing dipeptides and ornithine $\alpha$-ketoglutarate (OKGA; Steinhardt et al. 1984; Fürst et al. 1987; Wernerman et al. 1987; Wang et al. 1988; Karner \& Roth, 1990). Referred to variously as 'organ specific' substrates, 'metabolic drivers' and 'novel substrates', interpretation of findings from studies with such compounds requires some caution. This is so particularly when considering the quantitative aspects of $\mathrm{N}$ administration during nutritional support. We would suggest that for a given $\mathrm{N}$ substrate to be termed 'novel', observed gains in $\mathrm{N}$ metabolism (i.e. positive improvement in protein synthesis or balance) should be achieved only when it is demonstrated that such gains cannot be achieved by simply increasing the amount of standard $N$ administered. Many of the studies so far reported have shown benefits of, for example, branched-chain amino acids (Cerra et al. 1982), glutamine dipeptides (Stehle et al. 1989) and OKGA (Wernerman et al. 1987) when isonitrogenous $N$ sources were administered. In other words, for a given intake of $\mathrm{N}$ the use of these compounds results in superior $\mathrm{N}$ retention or balance, as compared with the unsubstituted or unaltered $N$ source; what has not been shown is that the demonstrated improvements in $N$ metabolism could be attained simply by increasing the intake of standard $\mathrm{N}$. In the 'cost effective' environment that we increasingly work in at present, it would seem important to ensure that before efforts are made by the industry to promote the widespread use of any 'novel' $N$ substrate, that clinical investigators have demonstrated that its benefits have not been achieved by more simply and more cost effectively increasing standard unsubstituted $\mathrm{N}$ intakes. Notwithstanding the previously stated comments, the reported findings with the $\mathrm{N}$ substrates described are of interest. It has seemed to us that the compound OKGA might satisfy our requirements as 'novel' $\mathrm{N}$ substrate.

\section{OKGA}

OKGA contains two moieties and is formulated as the ionic salt of $\alpha$-ketoglutarate (molar ratio 2:1) which dissociates in solution. As Fig. 1 shows, OKGA is of interest because the two moieties are substrates involved in both the Krebs cycle ( $\alpha$-ketoglutarate) and the urea cycle (ornithine). Moreover, ornithine itself acts as the link between the two metabolic processes. OKGA was developed initially in the 1960 s with the aim of reducing hyperammonaemia in patients with cirrhosis. The $\alpha$-ketoglutarate moiety was perceived to trap ammonia and the ornithine moiety to climinate the glutamate formed in the urea cycle. In recent years not only has the role of ammonia in the pathogenesis of hepatic encephalopathy been questioned, but the clinical results of controlled trials in cirrhotic patients were not impressive (Paris et al. 1970; Michel et al. 1971; Molimard et al. 1982). Despite this, however, it was noted that the nutritional status of the patients receiving OKGA improved (Tremolieres et al. 1972). 


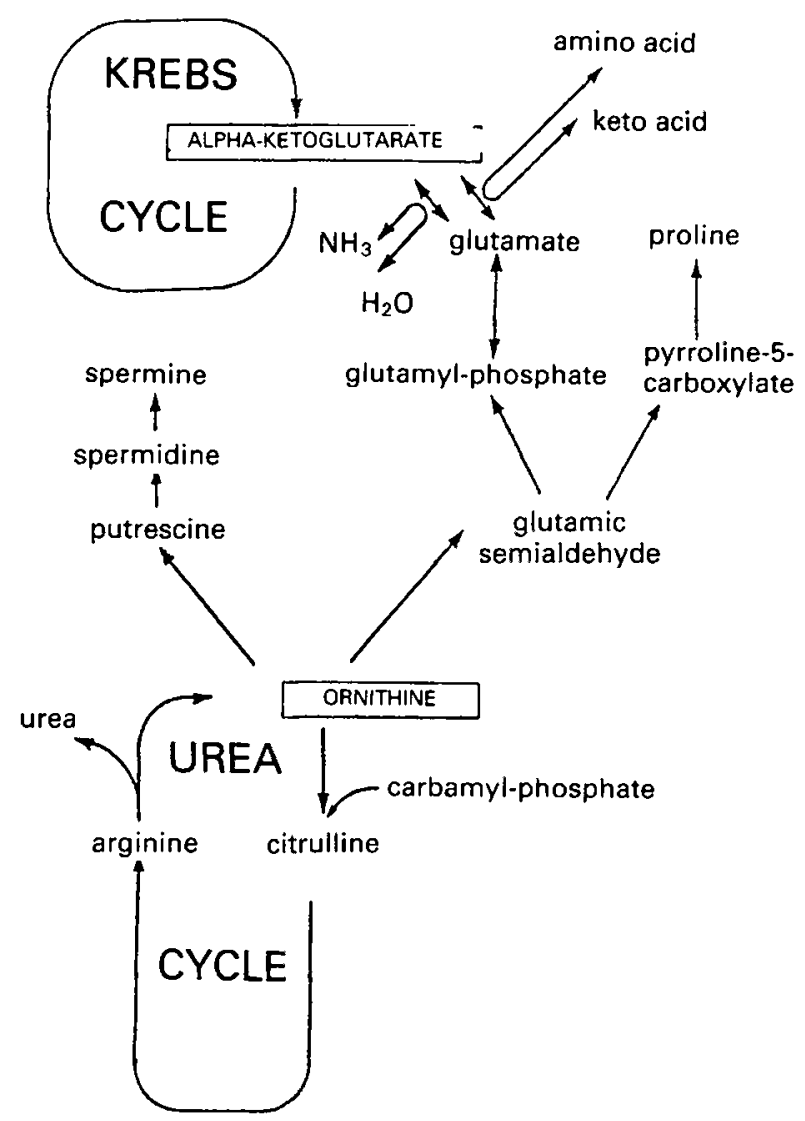

Fig. 1. Metabolic pathways of ornithine and $\alpha$-ketoglutarate.

The study that drew our attention to the possible beneficial clinical effects of OKGA was that published by Leander et al. (1985). Patients undergoing routine colorectal surgery were randomized to receive one to two isoenergetic isonitrogenous TPN regimens in the immediate post-operative phase. Control patients received $0 \cdot 15 \mathrm{~g}$ amino acid- $\mathrm{N} / \mathrm{kg}$ per $\mathrm{d}$. Treatment patients received the same regimen but with $2.5 \mathrm{~g}$ amino acid- $\mathrm{N}$ replaced with OKGA. Cumulative $\mathrm{N}$ balance over $5 \mathrm{~d}$ was significantly greater in the OKGA group (Leander et al. 1985). In a subsequent study based on a similar trial design, significantly better cumulative $\mathrm{N}$ balance on post-operative days $1-3$ was noted (Wernerman et al. 1987). In a further study, similar benefits to early post-operative $\mathrm{N}$ balance accrued when amino acid- $\mathrm{N}$ in the control group was replaced with $\alpha$-ketoglutarate (Wernerman et al. 1990). To date it has not been possible to determine whether such metabolic advantages of OKGA are mirrored by clinical advantages, in part because few clinicians would support a concept that routine peri-operative nutritional support was indicated in routine colorectal surgery. Moreover, as outlined previously, a separate control group in which added standard $\mathrm{N}$ was administered was not studied. Nevertheless, from the biochemical and metabolic stand-points the beneficial effect of OKGA on $\mathrm{N}$ balance is of interest. OKGA appears to exert its beneficial effects as a consequence of 
promoting reductions in output of urinary urea and ammonia. This seems likely to have occurred as a consequence of reduced skeletal muscle losses as evidenced by improved muscle polyribosome profiles and reduced 3-methyl histidine excretion (Chardon et al. 1986; Wernerman et al. 1987). At present there appears to be no unifying hypothesis for the action of OKGA in moderating traumatic $\mathrm{N}$ losses from skeletal muscle, although a number of concepts have been considered (Vaubourdolle et al. 1987; Grimble et al. 1989). Hammarqvist et al. (1990) have also demonstrated that OKGA-supplemented TPN will counter the post-operative decline in muscle free glutamine. What is clear, however, is that the action of OKGA is anti-catabolic. If, as seems likely, OKGA exerts a specific anti-catabolic activity, and that its positive effect on $\mathrm{N}$ metabolism cannot be reproduced by simply increasing the intake of standard $N$ sources, then OKGA would appear to satisfy the definition, set out previously, of a 'novel substrate'. It has seemed to us and others, that the potential of OKGA as a novel $N$ substrate may not be restricted to parenteral nutrition but be extended to enteral feeding (Cynober et al. 1984a; Pradoura et al. 1986). Although some studies of enteral administration of OKGA in healthy subjects and patients have been reported (Cynober et al. 1984b) and some significant effects in $\mathrm{N}$ balance noted (Demarcq et al. 1984; Leander et al. 1985), the results are not as clear cut as the findings reported in patients receiving TPN. Reasons for this relate not only to problems in study design, heterogeneity of the patient population studied and choice of end-points of the trials, but also in deciding what the total dose of OKGA should be, and whether it should be administered as a bolus dose or a continuous infusion.

When administering an enteral load of nutritional substrate decisions about modes of administration should take into account knowledge of absorption mechanisms and side effects. Our prime interest in OKGA, stimulated by the results of clinical studies referred to previously, has been to further evaluate its potential use as a novel enteral $\mathrm{N}$ substrate. Towards this aim we have sought not only to understand more about the mechanisms involved in its assimilation by the human gastrointestinal tract but also to define the tolerance of patients for this ionic salt. When embarking on a quest of defining mechanisms of absorption of any compound, the pitfalls of the oral tolerance technique have to be appreciated (Asatoor et al. 1971). We have, therefore, used an in vivo steady-state jejunal perfusion technique in normal human subjects (Sladen \& Dawson, 1969). As the ionic salt dissociates to OKGA in solution, isotonic test solutions containing OKGA were perfused over a range of concentrations. The kinetics of absorption of both compounds have the characteristics of an energy-dependent, carrier-mediated process, uptake of both compounds becoming saturable over the range of concentrations studied. The derived kinetic constants, $K_{t}$ (solute concentration required to half saturate the absorption process) and $V_{t}$ (theoretical maximum absorption rate), of both compounds indicate the presence of transport systems of low capacity and high affinity. It was, thus, considered important in view of these results to determine that the two moieties of the ionic salt OKGA do not share a common transport system, as in these circumstances competitive inhibition of uptake of one moieity by the other may occur. Subsequent jejunal perfusion studies confirmed that this was not the case (Payne-James et al. 1989b). L-Ornithine is a dibasic amino acid, and in a similar manner to the other dibasic amino acids, lysine and arginine it was found to have a deleterious effect on water and elcctrolyte transport, stimulating a net secretion when high concentrations were perfused (Hellier et al. 1973; Payne-James et al. 1988). In the 
context of enteral feeding our findings suggest that caution is needed when consideration is given to the dose of OKGA to be administered, and whether it should be given as a continuous infusion or a bolus. A low-capacity and high-affinity transport system suggests that while the small intestine has the capacity to absorb large quantities it will do so slowly. After oral ingestion of high loads of OKGA the concentrations of both moieties in the bulk phase of lumen contents are likely to be high relative to other nutritional substrates such as sugars, neutral amino acids and oligopeptides. In view of the fact that ornithine exerts a deleterious rather than beneficial effect on water and electrolyte absorption, water secretion (or at least a reduction in small intestinal water absorption) might be expected to occur which in turn could lead to abnormally high colonic inflows resulting in diarrhoea. Results of our subsequent enteral infusion studies in normal human subjects and studies of others have supported these conclusions as unacceptable diarrhoea occurred when $20 \mathrm{~g}$ bolus doses of OKGA were administered (Cynober et al. 1984b; Payne-James et al. 1989a). Based on our findings we believe that future clinical studies should involve the administration of lower loads of OKGA. This can be achieved either by frequently administering low bolus doses of OKGA or by mixing OKGA with enteral diets and administering the diets by constant infusion. Mindful that clinical investigation should be charged with demonstrating clinical as well as biochemical and metabolic efficacy, we are studying the clinical efficacy of enterally administered OKGA in patients admitted to our institution with fractured neck of femur. Such patients have previously been shown to benefit clinically from nutritional support administered via the enteral route (Bastow et al. 1983), and $\mathrm{N}$ losses established (Stableforth, 1986). Study design is based on randomizing patients not only to receive a standard ward diet or enteral feeding with the nitrogenous polymeric diets in which a proportion of $\mathrm{N}$ in one is replaced with OKGA, but also on one group receiving the same polymeric diet containing increased amounts of $\mathrm{N}$, thus ensuring that any possible benefits that accrue in the OKGA group cannot merely be achieved by simply increasing the amount of standard exogenous $\mathrm{N}$ administered, possibly more cost effectively.

\section{REFERENCES}

Asatoor, A. M., Crouchman, M. R. Harrison, A. R., Longbridge, L. W., Milne. M. D. \& Richards, A. J. (1971). Intestinal absorption of oligopeptides in cystinuria. Clinical Science 41, 23-33.

Bastow, M. D., Rawlings, J. \& Allison, S. P. (1983). Benefits of supplementary tube feeding after fractured neck of femur: a randomised controlled trial. British Medical Journal 287, 1589-1592.

Bistrian. B. R., Blackburn, G. L., Vitale, J., Cochran, D. \& Naylor, J. (1976). Prevalence of malnutrition in general medical patients. Journal of the American Medical Association 235, 1597.

Burns, H. J. G. (1988). Nutritional support in the peri-operative period. British Medical Bulletin 44, $357-373$.

Cerra, F. B., Upson, D., Angelico, R., Wiles, C., Lyons, J., Faulkenbach, L. \& Paysinger, J. (1982). Branched chains support post-operative protein synthesis. Surgery 92, 192-199.

Chardon, P., Nury, G., Kienlen, J. \& du Cailar, J. (1986). Nitrogen sparing effect of ornithine ketoglutarate (OKG) during total parenteral nutrition in stress state patients. Clinical Nutrition 6, Suppl., 132.

Cynober, L., Saizy, R., Nguyen Dinh, F., Lioret, L. \& Giboudeau, J. (1984a). Effect of enterally administered ornithine alpha ketoglutarate on plasma and urinary amino acid levels after burn injury. Journal of Trauma 24, 590-596.

Cynober, L., Vaubourdolle, M., Dore, A. \& Giboudeau, J. (1984b). Kinetics and metabolic effects of orally administered ornithine alpha-ketoglutarate in healthy subjects fed with a standardised regimen. American Journal of Clinical Nutrition 39, 514-519.

Demarcq. J. M., Delbar, M., Trochu, G. \& Crignon, J. J. (1984). Effets de l'alpha cetoglutarate d'ornithine sur l'etat nutritionnel des malades de reanimation. Cahiers Anesthesiologie 32, 3-6. 
Dominioni, L., Trocki, O., Fang, C. H. \& Alexander, J. W. (1985). Nitrogen balance and liver changes in burned guinea pigs undergoing prolonged high-protein enteral feeding. Surgical Forum 34, 99.

Elwyn, D. H., Kinney. J. M. \& Askanazi, J. (1981). Energy expenditure in surgical patients. Surgical Clinics of North America 61, 545-548.

Fürst, P., Albers, S. \& Stehle, P. (1987). Stress-induced intracellular glutamine depletion. The potential use of glutamine containing peptides in parenteral nutrition. In Dipeptides as New Substrates in Nutrition Therapy, pp. 117-136 [S. Adibi, W. Fekl and M. Oehmke, editors]. Munich: Karger.

Greenberg, G. R. Marliss, E. B., Anderson, G. H., Langer, B., Spence, W., Tovee, E. B. \& Jeejecbhoy, K. N. (1976). Protein-sparing therapy in post-operative patients: effects of added hypocaloric glucose or lipid. New England Journal of Medicine 294, 1411-1416.

Grimble, G. K., Payne-James, J. J., Rees, R. G. \& Silk, D. B. A. (1989). TPN: Novel energy substrates. Intensive Therapy and Clinical Monitoring 10, 108-113.

Hammarqvist, F., Wernerman, J., Ali, R. \& Vinnars, E. (1990). Effect of an amino acid solution enriched with branched chain amino acid or ornithine-ketoglutarate on the post-operative intracellular amino acid concentration of muscie. British Joumal of Surgery 77, 214-218.

Hartl, W. H., Jauch, K.-W., Herndon, D. N., Cohnert. T. U. \& Wolfe, R. R. (1990). Effect of low-dose bradykinin on glucose metabolism and nitrogen balance in surgical patients. Lancet 335, 69-71.

Hellier, M. D., Holdsworth, C. D. \& Perret, D. (1973). Dibasic amino acid absorption. Gastroenterology 65, $613-618$.

Hill, G. L. \& Church, J. (1984). Energy and protein requirements of general surgical patients requiring intravenous nutrition. British Journal of Surgery 71, 1-9.

Hill, G. L., Pickford, I. \& Young, G. A. (1977). Malnutrition in surgical patients. Lancet i, $689-692$.

Jones, B. J. M., Lees, R., Andrews, J., Frost, P. \& Silk, D. B. A. (1983). Comparison of an elemental and polymeric diet in patients with normal gastrointestinal function. Gut 24, 78-84.

Karner, J. \& Roth, E. (1990). Alanyl-glutamine infusions to patients with acute pancreatitis. Clinical Nutrition 9, 43-44.

Keohane, P. P., Attrill, H., Love, M.. Frost P. \& Silk, D. B. A. (1984). Relations between osmolality of dict and gastrointestinal side effects in enteral nutrition. British Medical Journal 288, 678-681

Leander, U.. Fürst, P., Vesterberg, K. \& Vinnars, E. (1985). Nitrogen sparing effect of Ornicetil in the immediate post-operative state. Clinical Nutrition 4, 43-51. .

MacFie, J., Smith, R. C. \& Hill, G. L. (1981). Glucose or fat as a non-protein energy source? A controlled trial in gastroenterological patients requiring parenteral nutrition. Gastroenterology 80, 103.

Manson, J. Mc. \& Wilmore, D. W. (1986). Positive nitrogen balance with human growth hormone and hypocaloric intravenous feeding. Surgery 100, 188-197.

Michel, H., Oge, P. \& Bertand, L. (1971). Action de l'alpha cetoglutarate d'ornithine sur l'hyperammoniemie du cirrhotique. Nouvelle Presse Medicine 19.867-868.

Molimard, R., Charpentier, C. \& Lemonnier, F. (1982). Modifications de l'aminoacidemie des cirrhotiques sous l'influence de sels d'ornithine. Annale Nutrition et Metabolisme 26, 25-36.

Neithercut, W. D., Smith. A. D. S., McAllister, J. M. \& La Ferla, G. A. (1987). Nutritional survey of patients in a general surgical ward: is there an effective predictor of malnutrition. Journal of Clinical Patholog. 40 , $803-807$.

Paris, J., Merveille, P. \& Molimard, R. (1970). L'alpha-cetoglutarate d'ornithine dans les encephalopathies des hepatiques. Nouvelle Presse Medicine 1, 1367-1368.

Payne-James, J. J., Grimble, G. K. Cahill, E., Ioannou. C. \& Silk, D. B. A. (1989a). Enteral administration of ornithine oxoglutarate (OKGA) in man: effects on hormone profiles and nitrogen metabolism. Journal of Parenteral and Enteral Nutrition 13, Suppl., A36.

Payne-James, J. J., Grimble, G. K., Cahill, E. \& Silk, D. B. A. (1988). Jejunal absorption of ornithine in man. Clinical Nutrition 7, Suppl., 18.

Payne-James, J. J., Grimble, G. K., Cahill, E. \& Silk, D. B. A. (1989b). Jejunal absorption of ornithine oxo-glutarate in man. Journal of Parenteral and Enteral Nutrition 13, Suppl., A104.

Payne-James, J. J. \& Silk, D. B. A. (1988). Enteral nutrition: background. indications and management. Baillieres Clinical Gastroenterology 24, 815-847.

Ponting, G. A., Halliday, D. Teale, J. D. \& Sim, A. J. W. (1988). Post-operative positive nitrogen balance with intravenous hyponutrition and growth hormone. Lancet $\mathrm{i}, 438-440$.

Pradoura, J. P., Carcassonne, Y. \& Spitalier, J. M. (1986). Double-blind randomised trial of L-ornithine alpha keto-glutarate enteral supplementation in operated patients with oropharynx cancer. Clinical Nutrition 6 . Suppl., P69. 
Rees, R. G. P.. Cooper. T. M., Beetham, R., Frost, P. G. \& Silk, D. B. A. (1989a). Influence of energy and nitrogen contents of enteral diets on nitrogen balance: a double-blind prospective controlled clinical trial. Gut 30, 123-129.

Rees, R. G., Payne-James, J. J. Grimble, G. K. \& Silk, D. B. A. (1989b). Energy requirements and nitrogen requirements in patients receiving nutritional support. Intensive Therapy and Clinical Monitoring 10 , 204-208.

Shanbhogue, L. K. R., Chwals, W. J., Weintraub, M., Blackburn, G. L. \& Bistrian, B. R. (1987). Parenteral nutrition in the surgical patient. British Journal of Surgery 74, 172-180.

Sladen, G. E. \& Dawson, A. M. (1969). Inter-relationships between the absorption of glucose, sodium and water by the normal human jejunum. Clinical Science 36, 119-137.

Stableforth, P. G. (1986). Supplemental feeds and nitrogen and calorie balance following femoral neck fracture. British Journal of Surgery 73, 651-655.

Stehle, P., Mertes, N., Puchstein, Ch., Zander, J., Albers, S. \& Lawin, P. (1989). Effect of parenteral glutamine loss and nitrogen balance after major surgery. Lancet $\mathbf{i}, 231-234$.

Stcinhardt, H. J.. Paleos, G. A.. Brandl, M.. Fekl, W. E. \& Adibi. S. A. (1984). Efficacy of a synthetic dipeptide mixture as the source of amino acids for total parenteral nutrition in a sub-human primate (baboon). (iastroenterology 86, 1562-1569.

Tremolieres, J., Scheggia, E. \& Flament, C. (1972). Effets de l'alpha-cetoglutarate d'ornithine sur le bilan azote et sur la vitesse d'oxydation del l'ethanol. Cahiers Nutrition et Dietetique 7, 2-7.

Vaubourdolle, M., Cynober, L., Lioret, N., Coudray-Lucas, C., Aussel, C., Saizy. R. \& Giboudeau, J. (1987). Influence of enterally administered ornithine alpha-ketoglutarate on hormonal patterns in burn patients. Burns 13, 349-356.

Wang, X.-D., Jacobs, D. O., Smith, R. J. \& Wilmore, D. W. (1988). Glutamine-enriched parenteral nutrition prevents mucosal atrophy following massive small-bowel resection. Surgical Forum 39, 44-46.

Wernerman, J., Hammarqvist, F., von der Decken, A. \& Vinnars, E. (1987). Ornithinc-alpha-ketoglutarate improves skeletal muscle protein synthesis as assessed by ribosome analysis and nitrogen use after surgery. Annals of Surgery 206, 674-678.

Wernerman, J., Hammarqvist, F., von der Decken, A. \& Vinnars, E. (1990). Analogies to glutamine in clinical practice. Clinical Nurition $9,41-43$.

Wilmore, D. W. (1989). The practice of clinical nutrition: how to prepare for the future. Journal of Parenteral and Enteral Nutrition 13, 337-343.

Ziegler, T. R., Young, L. S., Manson, J. Mc. \& Wilmore, D. W. (1988). Metabolic effects of recombinant human growth hormone in patients rcceiving parenteral nutrition. Annals of Surgery 208, 6-16. 